\title{
Single Finite Fourier Sine Integral Transform Method for the Flexural Analysis of Rectangular Kirchhoff Plate with Opposite Edges Simply Supported, Other Edges Clamped for the Case of Triangular Load Distribution
}

\author{
${ }^{1}$ Benjamin O. Mama, ${ }^{2 *}$ Onyedikachi A. Oguaghamba, ${ }^{3}$ Charles C. Ike \\ ${ }^{I}$ Department of Civil Engineering University of Nigeria, Nsukka, Enugu State, Nigeria. \\ ORCID: 0000-0002-0175-0060 \\ $2^{2 *}$ Department of Civil Engineering University of Nigeria, Nsukka, Enugu State, Nigeria. \\ Corresponding author, ORCID: 0000-0002-7480-28960077 \\ ${ }^{2}$ Department of Civil Engineering, Enugu State University of Science and Technology, Enugu.
} ORCID: 0000-0001-6952-0993

\begin{abstract}
This paper presents the single finite Fourier sine integral transform method for the flexural analysis of rectangular Kirchhoff plate with opposite edges simply supported, and the other edges clamped for the case of triangular load distribution on the plate domain. The finite sine transform method is adopted because the sinusoidal integral kernel function satisfies all the Dirichlet boundary conditions along the simply supported edges. The governing domain equation which is a nonhomogeneous biharmonic equation is converted by the transformation to an integral equation over the solution domain. The integral equation is reduced by the linearity properties of the transformation, Leibnitz rule and boundary conditions along the simply supported edges to ordinary differential equations (ODEs). Classical methods of solving ODEs in closed-form were used to obtain the solutions that satisfy the boundary conditions along the clamped edges. Thus exact solutions to the boundary value problem that satisfy the governing equation at all points in the solution domain as well as at all points along the four edges are obtained. The resulting expression for the deflection is a single infinite series with demonstrated rapidly convergent properties. The bending moments $M_{x x}, M_{y y}$ expressions were obtained using the bending moment-deflection relations as infinite series with demonstrated rapid convergence. The converged values of the maximum deflection and bending moments $M_{x x}, M_{y y}$ evaluated at the plate centre are in excellent agreement with the previous exact results to the problem obtained by researchers who used the Kantorovich-Vlasov method; Levy's method; and the superposition method.
\end{abstract}

Keyword: Single finite Fourier sine integral transform, method, Kirchhoff plate theory, Inhomogeneous biharmonic differential equation, Single infinite series, Deflection, Bending moment.

\section{INTRODUCTION}

Plate problems of bending, stability and vibration are important themes in structural analysis due to the extensive applications of plates in the fields of structural, mechanical, naval, marine, aeronautical, and aerospace engineering. The problems have attracted intensive research interest leading to the development of several theories of plate behaviour and several methods for the analytical and numerical treatment of plate problems.

Broadly, plates have been classified as thin, moderately thick and thick plates depending on the ratios of their transverse dimensions to the least inplane dimension. They have also been classified based on their material properties as anisotropic, isotropic, orthotropic or transversely isotropic or homogeneous, nonhomogeneous, linearly elastic or nonlinearly elastic $[1-10]$.

Formulations of governing theories for each of those classifications of plates have been made in the literature. Plate governing theories have been developed for thin plates, moderately thick plates and thick plates. They have also been developed for anisotropic plates, isotropic plates, homogeneous and nonhomogeneous plates that are either thin, moderately thick or thick.

Thin plate idealizations rely on the relative smallness of the transverse dimension of the plate compared to the lateral or inplane dimensions thus reducing the three-dimensional (3D) nature of plates to two-dimensional (2D) simplifications. This simplification has its attendant consequence of introduction of errors which become really insignificant when the ratio of the plate thickness to the least inplane dimension is less than 0.05 , which is the threshold for the definition of thin plates.

The following theories have been derived and formulated for plate problems: Kirchhoff plate theory, Mindlin plate theory, Reissner plate theory, Reddy plate theory, Levinson plate theory, shear deformation plate theories, and higher order shear deformation plate theories.

Formulations, development and solutions of moderately thick plate problems have been presented by amongst others, by Ike, [11], Ike [12], Ike et al [13], Nwoji et al [14], Ike [15], Nwoji et al [16] and Ike et al [17].

Plate problems have been solved using numerical and analytical methods. Some of the numerical techniques used in presenting and solving plate problems include: Ordinary Finite Difference Method by Ezeh et al [18], Finite Element Methods and Energy methods by Shames and Dym [2].

Some of the analytical methods that have been used for plate problems are (i) superposition methods; (ii) Navier double 
Fourier series method; (iii) Levy's single trigonometric series method; (iv) Galerkin-Vlasov method; (v) Ritz variational method; (vi) Kantorovich method and variants of the Kantorovich method and (vii) Fourier series methods:

Superposition methods have been used by Timoshenko and Woinowsky-Krieger [1]. Navier's double Fourier series (trigonometric series) method have been used for plate problems by Timoshenko and Woinowsky-Krieger, [1], and Szilard [7].

Levy's single trigonometric series method have been used for plate problems by Timoshenko and Woinowsky-Krieger [1], Shames and Dym [2].

Galerkin-Vlasov method have been used for plate problems by Osadebe et al [19], Nwoji et al [20], Ike [21], Mama and Ike [22], Onyia et al [23], Mama et al [24].

Ritz variational method has been used for plate problems by Ike [25], Ike [26] and Nwoji et al [27].

Kantorovich variational method has been used for plate problems by Ike [28], Ike and Nwoji [29], Nwoji et al [30], Onah et al [31], Ike and Mama [32], Ike et al [33].

Finite Fourier sine transform methods have been used to solve plate problems by Ike [34], Nwoji et al [35], Mama et al [36], Mama et al [37], Mama et al [38], Onah et al [39], Ike [40], Oguaghamba and Ike [41], and Onyia et al [42].

Other significant contributions to the formulation and solutions of plate problems include the following publications: Ghannadiasi and Noorzad [43], Bigdoli et al [44], Zargaripoor et al [45], Goodarzi et al [46], Javidi et al [47], Makvandi et al [48], Sayyad and Ghugal [49], Mirzapour et al [50], Shahabian et al [51], Abdollahzadeh and Ghobadi [52], Cuba et al [53] and Jahanpour and Roozbabani [54].

In this paper, the single finite Fourier sine integral transform method is used for the flexural analysis of rectangular thin plates with two opposite clamped edges and the other two edges simply supported for the case where the plate is subject to triangular load distribution over the entire domain. Though the methodology adopted has been previously applied by the authors to plate stability and flexural problems, this is a first attempt at applying the method to thin CSCS plate flexure problem under triangular load distribution.

\section{Justification for the use of the single finite Fourier sine integral transform method}

The single finite Fourier sine integral transform method is adopted for the study because the considered plate is simply supported along the two edges $x=0$ and $x=a$ and the sinusoidal kernel function in the transformation aproiri satisfies the Dirichlet boundary conditions along the edges, $x$ $=0$ and $x=a$. Thus, the method renders unnecessary prior selection of the shape function for solving the boundary value problem. Another justification, which is evident in past problems solved by the method is the great simplification offered by the use of the method in reducing the boundary value problem to ordinary differential equations and ultimately to algebraic problems [42].

\section{THEORY}

Kirchhoff small deflection thin plate theory is used for the plate flexure problem. The governing domain equation is given by the inhomogeneous biharmonic equation:

$D \nabla^{4} u_{z}(x, y)=p(x, y)$

where $D=\frac{E h^{3}}{12\left(1-\mu^{2}\right)}$

$D$ is the flexural rigidity of the plate, $u_{z}(x, y)$ is the transverse deflection of the plate, $p(x, y)$ is the distributed transverse load over the plate domain. $h$ is the plate thickness, $\mu$ is the Poisson's ratio of the plate material. $x$ and $y$ are the inplane Cartesian coordinates. $E$ is the Young's modulus of elasticity of the plate material.

$\nabla^{4}$ is the biharmonic operator given explicitly by:

$\nabla^{4}=\frac{\partial^{4}}{\partial x^{4}}+2 \frac{\partial^{4}}{\partial x^{2} \partial y^{2}}+\frac{\partial^{4}}{\partial y^{4}}$

The bending moments $M_{x x}$ and $M_{y y}$ are given in terms of transverse deflections $u_{z}(x, y)$ as:

$$
\begin{aligned}
& M_{x x}=-D\left(\frac{\partial^{2} u_{z}}{\partial x^{2}}+\mu \frac{\partial^{2} u_{z}}{\partial y^{2}}\right) \\
& M_{y y}=-D\left(\frac{\partial^{2} u_{z}}{\partial y^{2}}+\mu \frac{\partial^{2} u_{z}}{\partial x^{2}}\right)
\end{aligned}
$$

The CSCS thin plate considered is shown in Figure 1, which also shows the definition of coordinates and the applied triangular load over the plate.

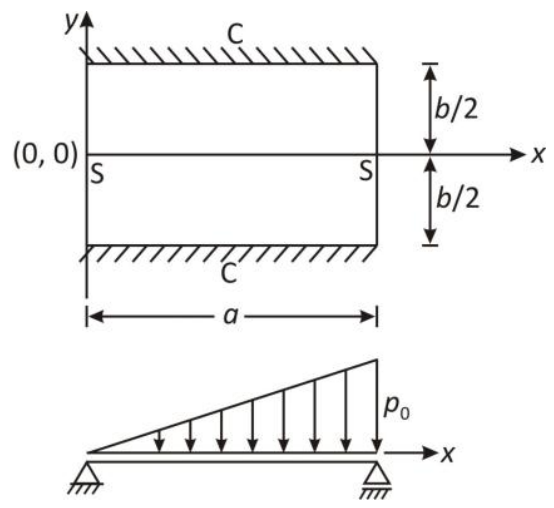

Figure 1: Kirchhoff CSCS plate subjected to triangular load distribution $p(x, y)=p_{0} x / a$

The coordinates system are chosen to take advantage of the symmetrical nature of the problem about the $x$ coordinate axis. The CSCS plate is simply supported at the edges $x=0$ and $x=$ $a$, and clamped at the edges $y=0$ and $y=b$. The triangular load distribution is given by

$$
p(x, y)=\frac{p_{0} x}{a}
$$

where $p_{0}$ is the intensity of the triangular load distribution at $x$ $=a$, as shown in Figure 1 .

The boundary conditions for the CSCS thin plate shown in Figure 1 are:

Along the simply supported edges $x=0, x=a$,

$u_{z}(x=0, y)=u_{z}(x=a, y)=0$ 
International Journal of Engineering Research and Technology. ISSN 0974-3154, Volume 13, Number 7 (2020), pp. 1802-1813

(C) International Research Publication House. https://dx.doi.org/10.37624/IJERT/13.7.2020.1802-1813

$\frac{\partial^{2} u_{z}}{\partial x^{2}}(x=0, y)=\frac{\partial^{2} u_{z}}{\partial x^{2}}(x=a, y)=0$

Along the clamped edges $y= \pm b / 2$,

$u_{z}(x, y= \pm b / 2)=0$

$\frac{\partial u_{z}}{\partial y}(x, y= \pm b / 2)=0$

\section{METHODOLOGY}

\subsection{Definitions}

The single finite Fourier sine integral transform of a function $v_{s}(x)$ of the independent variable $x$ denoted by $S_{n}(v(x))$ is defined as: $[55,56,57,58,59]$

$S_{n}(v(x))=\frac{2}{l} \int_{0}^{l} v(x) \sin \frac{n \pi x}{l} d x=V_{s}(n)$

where $0 \leq x \leq l$, and $n=1,2,3, \ldots$.

$n$ is the single finite Fourier sine integral transform parameter. Other scholarly publications on integral transformations are found in references listed as [60-63].

The transforms of the derivatives of $v(x)$ are found using integration by parts and Leibnitz rule as follows: [55, 56, 57, $58,59]$

$$
\begin{gathered}
S_{n}\left(v^{\prime}(x)\right)=S_{n}\left(\frac{d v(x)}{d x}\right)=v(x=l) \sin n \pi- \\
v(x=0) \sin 0-\frac{n \pi}{l} \frac{2}{l} \int_{0}^{l} \cos \frac{n \pi x}{l} d x \\
S_{n}\left(v^{\prime}(x)\right)=(v(x=l) \sin n \pi-v(x=0) \sin 0)- \\
\frac{n \pi}{l} C_{n} v(x)=-\frac{n \pi}{l} C_{n} v(x)=-\frac{n \pi}{l} V_{c}(n)
\end{gathered}
$$

$C_{n}(v(x))=V_{c}(n)$ is the single finite Fourier cosine transform of $v(x)$

$$
\begin{aligned}
& S_{n}\left(v^{\prime \prime}(x)\right)=S_{n}\left(\frac{d^{2} v(x)}{d x^{2}}\right)=-\left(\frac{n \pi}{l}\right)\left((-1)^{n} v(x=l)-\right. \\
& v(x=0))-\left(\frac{n \pi}{l}\right)^{2} \frac{2}{l} \int_{0}^{l} v(x) \sin \frac{n \pi x}{l} d x \\
& S_{n}\left(v^{\prime \prime}(x)\right)=-\left(\frac{n \pi}{l}\right)\left((-1)^{n} v(x=l)-v(x=0)\right)-\left(\frac{n \pi}{l}\right)^{2} V_{s}(n) \\
& S_{n}\left(v^{\prime \prime \prime}(x)\right)=-\left(\frac{n \pi}{l}\right)\left((-1)^{n} \frac{d v}{d x}(x=l)-\frac{d v}{d x}(x=0)\right)+ \\
& \quad\left(\frac{n \pi}{l}\right)^{3} \frac{2}{l} \int_{0}^{l} v(x) \cos \frac{n \pi x}{l} d x
\end{aligned}
$$

$$
S_{n}\left(v^{\prime \prime \prime}(x)\right)=-\left(\frac{n \pi}{l}\right)\left((-1)^{n} v^{\prime}(x=l)-v^{\prime}(x=0)\right)+\left(\frac{n \pi}{l}\right)^{3} V_{c}(n)
$$

$$
S_{n}\left(v^{i v}(x)\right)=S_{n} \frac{d^{4} v(x)}{d x^{4}}=\left(\frac{n \pi}{l}\right)^{4} \frac{2}{l} \int_{0}^{l} v(x) \sin \frac{n \pi x}{l} d x+
$$

$$
\begin{aligned}
& \left(\frac{n \pi}{l}\right)^{3}\left(v(x=l)(-1)^{n}-v(x=0)\right)- \\
& \left(\frac{n \pi}{l}\right)\left((-1)^{n} v^{\prime \prime}(x=l)-v^{\prime \prime}(x=0)\right)
\end{aligned}
$$

When the function $v$ is a function of two independent variables $v(x, y)$, we have:

$$
\begin{aligned}
& S_{n}(v(x, y))=\frac{2}{l} \int_{0}^{l} v(x, y) \sin \frac{n \pi x}{l} d x=V_{s}(n, y) \\
& S_{n}\left(\frac{\partial^{2} v(x, y)}{\partial x^{2}}\right)=-\left(\frac{n \pi}{l}\right)\left((-1)^{n} v(x=l, y)-v(x=0, y)\right)- \\
& \quad\left(\frac{n \pi}{l}\right)^{2} V_{s}(n, y) \\
& S_{n}\left(\frac{\partial^{2} v}{\partial x^{4}}(x, y)\right)=\left(\frac{n \pi}{l}\right)^{4} V_{s}(n, y)+ \\
& \left(\frac{n \pi}{l}\right)^{3}\left((-1)^{n}(v(x=l, y)-v(x=0, y))-\right. \\
& \left(\frac{n \pi}{l}\right)\left((-1)^{n} v^{\prime \prime}(x=l, y)-v^{\prime \prime}(x=0, y)\right)
\end{aligned}
$$

For problems with Dirichlet boundary conditions,

$v(x=l, y)=v(x=0, y)=0$

$v^{\prime \prime}(x=l, y)=v^{\prime \prime}(x=0, y)=0$

The single finite Fourier sine integral transforms of the second and fourth derivatives of $v(x, y)$ with respect to $x$ simplify greatly to:

$$
\begin{aligned}
& S_{n}\left(\frac{\partial^{2} v(x, y)}{\partial x^{2}}\right)=-\left(\frac{n \pi}{l}\right)^{2} V_{s}(n, y) \\
& S_{n} \frac{\partial^{4} v(x, y)}{\partial x^{4}}=\left(\frac{n \pi}{l}\right)^{4} V_{s}(n, y)
\end{aligned}
$$

\subsection{Single finite Fourier sine integral transformation of the governing domain equation}

The partial differential equation (PDE) for the domain for the problem considered is given explicitly by the fourth order inhomogeneous equation:

$$
\begin{aligned}
& D\left(\frac{\partial^{4} u_{z}}{\partial x^{4}}+2 \frac{\partial^{4} u_{z}}{\partial x^{2} \partial y^{2}}+\frac{\partial^{4} u_{z}}{\partial y^{4}}\right)=p(x, y)=\frac{p_{0} x}{a} \\
& \text { or, } \frac{\partial^{4} u_{z}}{\partial x^{4}}+2 \frac{\partial^{4} u_{z}}{\partial x^{2} \partial y^{2}}+\frac{\partial^{4} u_{z}}{\partial y^{4}}-\frac{p_{0} x}{D a}=0
\end{aligned}
$$

Application of the transformation gives the integral equation:

$$
\frac{2}{a} \int_{0}^{a}\left(\frac{\partial^{4} u_{z}}{\partial x^{4}}+\frac{2 \partial^{4} u_{z}}{\partial x^{2} \partial y^{2}}+\frac{\partial^{4} u_{z}}{\partial y^{4}}-\frac{p_{0} x}{D a}\right) \sin \frac{n \pi x}{a} d x=0
$$

From the linearity properties of the transformation and Leibnitz rule, the integral equation becomes the following inhomogeneous ordinary differential equation (ODE):

$$
\begin{gathered}
\left(\frac{n \pi}{a}\right)^{4} \bar{U}_{z}(n, y)-2\left(\frac{n \pi}{a}\right)^{2} \frac{d^{2}}{d y^{2}} \bar{U}_{z}(n, y)+\frac{d^{4}}{d y^{4}} \bar{U}_{z}(n, y)- \\
\frac{2 p_{0}}{D a^{2}} \int_{0}^{a} x \sin \frac{n \pi x}{a} d x=0
\end{gathered}
$$


where $\bar{U}_{z}(n, y)$ is the single finite Fourier sine integral transform of $u_{z}(x, y)$, and is given by:

$\bar{U}_{z}(n, y)=\frac{2}{a} \int_{0}^{a} u_{z}(x, y) \sin \frac{n \pi x}{a} d x$

The ordinary differential equation (ODE) becomes upon evaluating the integral term:

$$
\begin{aligned}
\frac{d^{4} \bar{U}_{z}}{d y^{4}}(n, y)-2\left(\frac{n \pi}{a}\right)^{2} \frac{d^{2} \bar{U}_{z}}{d y^{2}}(n, y)+ \\
\left(\frac{n \pi}{a}\right)^{4} \bar{U}_{z}(n, y)=\frac{2 p_{0}(-1)^{n+1}}{n \pi D}
\end{aligned}
$$

The solution to Equation (31) is the sum of the homogeneous solution and the particular integral.

\section{RESULTS}

\section{Homogeneous solution}

The homogeneous solution to Equation (31) is sought in exponential form. Thus, let

$\bar{U}_{z h}(n, y)=\Gamma \exp \lambda y$

where $\Gamma$ and $\lambda$ are parameters of the assumed (trial) homogeneous solution.

For $\bar{U}_{z h}(n, y)$ to be solution, the homogeneous differential equation becomes

$\left(\lambda^{4}-2\left(\frac{n \pi}{a}\right)^{2}+\left(\frac{n \pi}{a}\right)^{4}\right) \Gamma e^{\lambda y}=0$

For nontrivial solutions $\Gamma e^{\lambda y} \neq 0$

Hence,

$\lambda^{4}-2\left(\frac{n \pi}{a}\right)^{2}+\left(\frac{n \pi}{a}\right)^{4}=\left(\lambda^{2}-\left(\frac{n \pi}{a}\right)^{2}\right)^{2}=0$

The solutions for $\lambda$ are:

$$
\lambda_{1,2}=\frac{n \pi}{a} \text { twice }
$$

$\lambda_{3,4}=-\left(\frac{n \pi}{a}\right)$ twice

The homogeneous solution becomes:

$$
\begin{aligned}
\bar{U}_{z h}(n, y)=c_{1 n} \cosh \frac{n \pi y}{a}+c_{2 n} \frac{n \pi y}{a} \sinh \frac{n \pi y}{a}+ \\
c_{3 n} \frac{n \pi y}{a} \cosh \frac{n \pi y}{a}+c_{4 n} \sinh \frac{n \pi y}{a}
\end{aligned}
$$

where $c_{1 n}, c_{2 n}, c_{3 n}$ and $c_{4 n}$ are integration constants.

The problem considered is symmetrical about the $x$ axis. Hence, $\bar{U}_{z h}(n, y)$ is expected to be a symmetrical function in $y$.

The symmetry of $\bar{U}_{z h}(n, y)$, demands that:

$c_{3 n}=c_{4 n}=0$

Hence the homogeneous solution becomes:

$\bar{U}_{z h}(n, y)=c_{1 n} \cosh \frac{n \pi y}{a}+c_{2 n} \frac{n \pi y}{a} \sinh \frac{n \pi y}{a}$
Particular solution $\bar{U}_{z p}(n, y)$

The applied load $p(x, y)=p_{0} x / a$ does not depend upon $y$. Hence we expect that the derivatives of the particular solution $\bar{U}_{z p}(n, y)$ with respect to $y$ would vanish.

According:

$\bar{U}_{z p}^{\prime \prime}(n, y)=U_{z p}^{i v}(n, y)=0$

Then, Equation (23) becomes:

$\left(\frac{n \pi}{a}\right)^{4} \bar{U}_{z p}(n, y)=\frac{2 p_{0}(-1)^{n+1}}{n \pi D}$

Solving,

$\bar{U}_{z p}(n, y)=\frac{2 p_{0} a^{4}(-1)^{n+1}}{(n \pi)^{5} D}$

\section{General solutions $\bar{U}_{z}(n, y)$}

The general solution in the finite integral transform space is found as the superposition of the homogeneous solution and the particular solution.

Then,

$$
\begin{aligned}
& \bar{U}_{z}(n, y)=\bar{U}_{z h}(n, y)+\bar{U}_{z p}(n, y) \\
& \bar{U}_{z}(n, y)=c_{1 n} \cosh \frac{n \pi y}{a}+c_{2 n} \frac{n \pi y}{a} \sinh \frac{n \pi y}{a}+\frac{2 p_{0} a^{4}}{D} \frac{(-1)^{n+1}}{(n \pi)^{5}}
\end{aligned}
$$

\section{General solution for transverse deflection in the physical domain}

The general solution for transverse deflection in the problem domain is found by the inverse finite Fourier sine integral transform of $\bar{U}_{z}(n, y)$. By inversion,

$$
u_{z}(n, y)=\sum_{n=1}^{\infty} \bar{U}_{z}(n, y) \sin \frac{n \pi x}{a}
$$

Then, substituting the expression for $\bar{U}_{z}(n, y)$ from Equation (44), we obtain the single infinite series:

$$
\begin{gathered}
u_{z}(x, y)=\sum_{n=1}^{\infty}\left(c_{1 n} \cosh \frac{n \pi y}{a}+c_{2 n} \frac{n \pi y}{a} \sinh \frac{n \pi y}{a}+\right. \\
\left.\frac{2 p_{0} a^{4}}{D} \frac{(-1)^{n+1}}{(n \pi)^{5}}\right) \sin \frac{n \pi x}{a}
\end{gathered}
$$

The general solution for $u_{z}(x, y)$ is expressed in terms of constants of integration $c_{1 n}$ and $c_{2 n}$ which are found using the boundary conditions along the clamped edges $(y= \pm b / 2)$ of the plate.

\section{Application of boundary conditions}

Substituting Equation (46) in Equation (9) we have the following boundary condition equation:

$$
u_{z}\left(x, y= \pm \frac{b}{2}\right)=\sum_{n=1}^{\infty}\left(c_{1 n} \cosh \frac{n \pi b}{2 a}+c_{2 n} \frac{n \pi b}{2 a} \sinh \frac{n \pi b}{2 a}+\right.
$$


International Journal of Engineering Research and Technology. ISSN 0974-3154, Volume 13, Number 7 (2020), pp. 1802-1813

(C) International Research Publication House. https://dx.doi.org/10.37624/IJERT/13.7.2020.1802-1813

$$
\left.\frac{2 p_{0} a^{4}}{D} \frac{(-1)^{n+1}}{(n \pi)^{5}}\right) \sin \frac{n \pi x}{a}=0
$$

Substitution of Equation (46) in Equation (10) gives another boundary condition equation regarding slopes at the clamped edges as follows:

$$
\begin{aligned}
& \frac{\partial u_{z}}{\partial z}\left(x, y= \pm \frac{b}{2}\right)=\sum_{n=1}^{\infty}\left(c_{1 n} \frac{n \pi}{a} \sinh \frac{n \pi b}{2 a}+\right. \\
& \left.c_{2 n} \frac{n \pi}{a}\left(\frac{n \pi b}{2 a} \cosh \frac{n \pi b}{2 a}+\sinh \frac{n \pi b}{2 a}\right)\right) \sin \frac{n \pi x}{a}=0
\end{aligned}
$$

Equation (48) is simplified to:

$c_{1 n} \frac{n \pi}{a} \sinh \frac{n \pi b}{2 a}=-c_{2 n} \frac{n \pi}{a}\left(\frac{n \pi b}{2 a} \cosh \frac{n \pi b}{2 a}+\sinh \frac{n \pi b}{2 a}\right)$

Hence,

$c_{1 n}=\frac{-c_{2 n} \frac{n \pi}{a}\left(\frac{n \pi b}{2 a} \cosh \frac{n \pi b}{2 a}+\sinh \frac{n \pi b}{2 a}\right)}{\frac{n \pi}{a} \sinh \frac{n \pi b}{2 a}}$

Simplifying further, Equation (50) becomes:

$c_{1 n}=-c_{2 n}\left(\frac{n \pi b}{2 a} \frac{\cosh \frac{n \pi b}{2 a}}{\sinh \frac{n \pi b}{2 a}}+1\right)$

Equation (47) simplifies to:

$c_{1 n} \cosh \frac{n \pi b}{2 a}+c_{2 n} \frac{n \pi b}{2 a} \sinh \frac{n \pi b}{2 a}=-\frac{2 p_{0} a^{4}}{D} \frac{(-1)^{n+1}}{(n \pi)^{5}}$

Substituting $c_{1 n}$ in Equation (51) into Equation (52) gives:

$$
\begin{gathered}
-c_{2 n}\left(\frac{n \pi b}{2 a} \frac{\cosh \frac{n \pi b}{2 a}}{\sinh \frac{n \pi b}{2 a}}+1\right) \cosh \frac{n \pi b}{2 a}+c_{2 n} \frac{n \pi b}{2 a} \sinh \frac{n \pi b}{2 a} \\
=\frac{-2 p_{0} a^{4}}{D} \frac{(-1)^{n+1}}{(n \pi)^{5}}
\end{gathered}
$$

Simplifying,

$$
\begin{gathered}
-c_{2 n} \frac{n \pi b}{2 a} \frac{\cosh ^{2} \frac{n \pi b}{2 a}}{\sinh \frac{n \pi b}{2 a}}-c_{2 n} \cosh \frac{n \pi b}{2 a}+c_{2 n} \frac{n \pi b}{2 a} \sinh \frac{n \pi b}{2 a} \\
=\frac{-2 p_{0} a^{4}}{D} \frac{(-1)^{n+1}}{(n \pi)^{5}}
\end{gathered}
$$

Further simplification gives:

$$
\begin{gathered}
c_{2 n} \frac{n \pi b}{2 a}\left(\sinh \frac{n \pi b}{2 a}-\frac{\cosh ^{2} \frac{n \pi b}{2 a}}{\sinh \frac{n \pi b}{2 a}}\right)-c_{2 n} \cosh \frac{n \pi b}{2 a} \\
=\frac{-2 p_{0} a^{4}}{D} \frac{(-1)^{n+1}}{(n \pi)^{5}}
\end{gathered}
$$

Further simplification of Equation (55) yields:

$$
c_{2 n} \frac{n \pi b}{2 a}\left(\frac{\sinh ^{2} \frac{n \pi b}{2 a}-\cosh ^{2} \frac{n \pi b}{2 a}}{\sinh \frac{n \pi b}{2 a}}\right)-c_{2 n} \cosh \frac{n \pi b}{2 a}
$$

$$
=-\frac{2 p_{0} a^{4}}{D} \frac{(-1)^{n+1}}{(n \pi)^{5}}
$$

We recall the hyperbolic identity:

$\sinh ^{2} \theta-\cosh ^{2} \theta=-1$

Using the hyperbolic identity in Equation (57), Equation (56) becomes:

$$
-c_{2 n} \frac{n \pi b}{2 a} \frac{1}{\sinh \frac{n \pi b}{2 a}}-c_{2 n} \cosh \frac{n \pi b}{2 a}=\frac{-2 p_{0} a^{4}}{D} \frac{(-1)^{n+1}}{(n \pi)^{5}}
$$

Thus,

$c_{2 n}\left(\frac{n \pi b}{2 a} \frac{1}{\sinh \frac{n \pi b}{2 a}}+\cosh \frac{n \pi b}{2 a}\right)=c_{2 n} F_{1}=\frac{2 p_{0} a^{4}}{D} \frac{(-1)^{n+1}}{(n \pi)^{5}}$

where, $F_{1}=\frac{n \pi b}{2 a} \frac{1}{\sinh \frac{n \pi b}{2 a}}+\cosh \frac{n \pi b}{2 a}$

Then $c_{2 n}=\frac{2 p_{0} a^{4}}{D} \frac{(-1)^{n+1}}{(n \pi)^{5}} \frac{1}{F_{1}}$

Then,

$c_{1 n}=\frac{-2 p_{0} a^{4}(-1)^{n+1}}{D(n \pi)^{5} F_{1}}\left(1+\frac{n \pi b}{2 a} \operatorname{coth} \frac{n \pi b}{2 a}\right)$

In compact form, Equation (62) is expressed as:

$c_{1 n}=\frac{-2 p_{0} a^{4}(-1)^{n+1} F_{2}}{D(n \pi)^{5} F_{1}}$

where,

$F_{2}=1+\frac{n \pi b}{2 a} \operatorname{coth} \frac{n \pi b}{2 a}$

Thus, the transverse deflection is determined as the single infinite series:

$$
\begin{aligned}
& u_{z}(x, y)=\sum_{n=1}^{\infty}\left\{\frac{-2 p_{0} a^{4}(-1)^{n+1}}{D(n \pi)^{5} F_{1}} F_{2} \cosh \frac{n \pi y}{a}+\right. \\
& \left.\frac{2 p_{0} a^{4}(-1)^{n+1}}{D(n \pi)^{5}} \frac{n \pi y}{a} \sinh \frac{n \pi y}{a}+\frac{2 p_{0} a^{4}(-1)^{n+1}}{D(n \pi)^{5}}\right\} \sin \frac{n \pi x}{a}
\end{aligned}
$$

From Equation (65) it is confirmed that the transverse deflection expression satisfies all the Dirichlet boundary conditions along the simply supported edges given as:

$$
\begin{aligned}
\frac{\partial^{2} u_{z}}{\partial x^{2}}(x=0, y)=\frac{\partial^{2} u_{z}}{\partial x^{2}}(x=a, y) & =u_{z}(x=0, y) \\
& =u_{z}(x=a, y)=0
\end{aligned}
$$

Since, $\left.\sin \frac{n \pi x}{a}\right|_{x=0}=0=\left.\sin \frac{n \pi x}{a}\right|_{x=a}$

\section{Deflection at the centre of the plate}

At the centre of the plate, $x=a / 2, y=0$, and the deflection at the plate centre is obtained by substitution of the centre coordinates into Equation (65) to obtain:

$u_{z}\left(x=\frac{a}{2}, y=0\right)=\sum_{n=1}^{\infty}\left\{\frac{-2 p_{0} a^{4}(-1)^{n+1}}{D(n \pi)^{5} F_{1}} F_{2} \cosh 0+\right.$ 
International Journal of Engineering Research and Technology. ISSN 0974-3154, Volume 13, Number 7 (2020), pp. 1802-1813

(C) International Research Publication House. https://dx.doi.org/10.37624/IJERT/13.7.2020.1802-1813

$$
\left.\frac{2 p_{0} a^{4}(-1)^{n+1}}{D(n \pi)^{5} F_{1}} 0+\frac{2 p_{0} a^{4}(-1)^{n+1}}{D(n \pi)^{5}}\right\} \sin \frac{n \pi}{2}
$$

Simplification of the series expression in Equation (66) gives:

$$
u_{z}\left(x=\frac{a}{2}, y=0\right)=\sum_{n=1}^{\infty} \frac{2 p_{0} a^{4}(-1)^{n+1}}{D(n \pi)^{5}}\left(1-\frac{F_{2}}{F_{1}}\right)
$$

Further simplification by factoring out the constants in Equation (67) gives:

$u_{z}\left(x=\frac{a}{2}, y=0\right)=\frac{p_{0} a^{4}}{D} \sum_{n=1}^{\infty} \frac{2(-1)^{n+1}}{(n \pi)^{5}}\left(1-\frac{F_{2}}{F_{1}}\right)$

The expression for the deflection of the centre of the plate can be given in general as:

$u_{z}\left(x=\frac{a}{2}, y=0\right)=\alpha_{1} \frac{p_{0} a^{4}}{D}$

where $\alpha_{1}=\sum_{n=1}^{\infty} \frac{2(-1)^{n+1}}{(n \pi)^{5}}\left(1-\frac{F_{2}}{F_{1}}\right)$

$\alpha_{1}$ is the deflection coefficient for the centre of rectangular CSCS Kirchhoff plate subjected to triangular load distribution given by $p(x, y)=p_{0} x / a$.

\section{Bending moment distributions}

By partial differentiations of $u_{z}(x, y)$, we have:

$$
\begin{aligned}
& \frac{\partial^{2} u_{z}}{\partial x^{2}}=-\sum_{n=1}^{\infty}\left(c_{1 n} \cosh \frac{n \pi y}{a}+c_{2 n} \frac{n \pi y}{a} \sinh \frac{n \pi y}{a}+\right. \\
& \left.\frac{2 p_{0} a^{4}(-1)^{n+1}}{D(n \pi)^{5}}\right)\left(\frac{n \pi}{a}\right)^{2} \sin \frac{n \pi x}{a} \\
& \frac{\partial^{2} u_{z}}{\partial y^{2}}=\sum_{n=1}^{\infty}\left\{c_{1 n}\left(\frac{n \pi}{a}\right)^{2} \cosh \frac{n \pi y}{a}+\right. \\
& \left.c_{2 n}\left(\left(\frac{n \pi}{a}\right)^{3} y \sinh \frac{n \pi y}{a}+2\left(\frac{n \pi}{a}\right)^{2} \cosh \frac{n \pi y}{a}\right)\right\} \sin \frac{n \pi x}{a} \\
& \frac{\partial^{2} u_{x}}{\partial x^{2}}\left(x=\frac{a}{2}, y=0\right)= \\
& \quad-\sum_{n=1}^{\infty}\left(c_{1 n} \cosh 0+\frac{2 p_{0} a^{4}(-1)^{n+1}}{D(n \pi)^{5}}\right)\left(\frac{n \pi}{a}\right)^{2} \sin \frac{n \pi}{2}
\end{aligned}
$$

$\frac{\partial^{2} u_{z}}{\partial x^{2}}\left(x=\frac{a}{2}, y=0\right)=$

$$
-\sum_{n=1}^{\infty}\left(c_{1 n}+\frac{2 p_{0} a^{4}(-1)^{n+1}}{D(n \pi)^{5}}\right)\left(\frac{n \pi}{a}\right)^{2} \sin \frac{n \pi}{2}
$$

$$
\begin{gathered}
\frac{\partial^{2} u_{z}}{\partial y^{2}}\left(x=\frac{a}{2}, y=0\right)=\sum_{n=1}^{\infty}\left\{c_{1 n}\left(\frac{n \pi}{a}\right)^{2}+c_{2 n}\left(2\left(\frac{n \pi}{a}\right)^{2}\right)\right\} \sin \frac{n \pi}{2} \\
=\sum_{n=1}^{\infty}\left(c_{1 n}+2 c_{2 n}\right)\left(\frac{n \pi}{a}\right)^{2} \sin \frac{n \pi}{2}
\end{gathered}
$$

Hence at the plate centre, the bending moments $M_{x x}$ and $M_{y y}$ are obtained by substituting Equations (74) and (75) into Equations (4) and (5) and simplifying:

$$
M_{x x}=-D \sum_{n=1}^{\infty}\left(\frac{n \pi}{a}\right)^{2}\left\{\mu\left(c_{1 n}+2 c_{2 n}\right)-c_{1 n}-\frac{2 p_{0} a^{4}(-1)^{n+1}}{D(n \pi)^{5}}\right\} \sin \frac{n \pi}{2}
$$

$M_{x x}$ expressed by Equation (76) is presented using bending moment coefficients $\alpha_{2}$ and $\alpha_{3}$ as:

$M_{x x}=\alpha_{2} p_{0} a^{2}=\alpha_{3} p_{0} b^{2}$

$\alpha_{2}$ is the bending moment coefficient for $M_{x x}$ at the plate centre, when $M_{x x}$ is expressed using $a$, and $\alpha_{3}$ is the bending moment coefficient for $M_{x x}$ at the plate centre when $M_{x x}$ is expressed using $b$.

$M_{y y}=-D \sum_{n=1}^{\infty}\left(\frac{n \pi}{a}\right)^{2}\left\{\left(c_{1 n}+2 c_{2 n}\right)-\mu\left(c_{1 n}+\frac{2 p_{0} a^{4}(-1)^{n+1}}{D(n \pi)^{5}}\right)\right\} \sin \frac{n \pi}{2}$

$M_{y y}$ expressed by Equation (78) is presented using bending moment coefficients $\alpha_{4}$ and $\alpha_{5}$ as:

$M_{y y}=\alpha_{4} p_{0} a^{2}=\alpha_{5} p_{0} b^{2}$

$\alpha_{4}$ is the bending moment coefficient for $M_{y y}$ at the plate centre where $M_{y y}$ is expressed using $a, \alpha_{5}$ is the bending moment coefficient for $M_{y y}$ at the plate centre where $M_{y y}$ is expressed using $b$.

\section{Solutions for square CSCS plates}

For square CSCSplates $b / a=1$

$$
\begin{aligned}
& F_{1}\left(\frac{b}{a}=1\right)=\frac{n \pi}{2} \frac{1}{\sinh \frac{n \pi}{2}}+\cosh \frac{n \pi}{2} \\
& F_{2}\left(\frac{b}{a}=1\right)=1+\frac{n \pi}{2} \operatorname{coth} \frac{n \pi}{2} \\
& c_{1 n}\left(\frac{b}{a}=1\right)=\frac{-2 p_{0} a^{4}(-1)^{n+1}}{D(n \pi)^{5}} \frac{\left(\frac{n \pi}{2} \frac{1}{\sinh \frac{n \pi}{2}}+\cosh \frac{n \pi}{2}\right)}{\left(1+\frac{n \pi}{2} \operatorname{coth} \frac{n \pi}{2}\right)} \\
& c_{2 n}\left(\frac{b}{a}=1\right)=\frac{2 p_{0} a^{4}(-1)^{n+1}}{D(n \pi)^{5}}\left(\frac{1}{\frac{n \pi}{2} \frac{1}{\sinh \frac{n \pi}{2}}+\cosh \frac{n \pi}{2}}\right)
\end{aligned}
$$

Thus, $u_{z}(x, y), M_{x x}$ and $M_{y y}$ can be calculated for square CSCS plates from the obtained values of $F_{1}, F_{2}, c_{1 n}$ and $c_{2 n}$. Similarly, for any plate aspect ratio, $F_{1}, F_{2}, c_{1 n}, c_{2 n}$ are calculated and $u_{z}(x, y), M_{x x}, M_{y y}$ determined. An illustration of the solution obtained for a one term series approximation is presented for square CSCS plates. For the one term series approximation, $n=1$

$$
\begin{aligned}
& F_{1}\left(n=1, \frac{b}{a}=1\right)=\frac{\pi}{2} \frac{1}{\sinh \frac{\pi}{2}}+\cosh \frac{\pi}{2}=3.19175 \\
& F_{2}\left(n=1, \frac{b}{a}=1\right)=1+\frac{\pi}{2} \operatorname{coth} \frac{\pi}{2}=2.71269
\end{aligned}
$$

Then,

$$
u_{z}\left(n=1, \frac{b}{a}=1\right)=\frac{2 p_{0} a^{4}(-1)^{2}}{D \pi^{5}}\left(1-\frac{2.71269}{3.19175}\right)
$$


International Journal of Engineering Research and Technology. ISSN 0974-3154, Volume 13, Number 7 (2020), pp. 1802-1813

(C) International Research Publication House. https://dx.doi.org/10.37624/IJERT/13.7.2020.1802-1813

$$
\begin{aligned}
& =9.8093 \times 10^{-4} \frac{p_{0} a^{4}}{D} \\
& c_{1 n}\left(n=1, \frac{b}{a}=1\right)=\frac{-2 p_{0} a^{4}(-1)^{2} F_{2}}{D \pi^{5} F_{1}}=-5.5546 \times 10^{-3} \frac{p_{0} a^{4}}{D} \\
& c_{2 n}\left(n=1, \frac{b}{a}=1\right)=\frac{2 p_{0} a^{4}(-1)^{2}}{D \pi^{5} F_{1}}=2.0476 \times 10^{-3} \frac{p_{0} a^{4}}{D}(88) \\
& M_{x x}\left(\frac{b}{a}=1, n=1\right)= \\
& -D\left(\frac{\pi}{a}\right)^{2}\left(0.3\left(c_{1}+2 c_{2}\right)-c_{1}-\frac{2 p_{0} a^{4}}{D \pi^{5}}\right)=0.01402 p_{0} a^{2}(89) \\
& M_{y y}\left(n=1, \frac{b}{a}=1\right)= \\
& -D\left(\frac{\pi}{a}\right)^{2}\left(c_{1}+2 c_{2}-0.3\left(c_{1}+\frac{2}{\pi^{5}}\right)\right)=0.017307 p_{0} a^{2}
\end{aligned}
$$

Table 1: Converged results for the expression for deflections evaluated at the centre of rectangular thin CSCS plate under triangular load distribution $p(x, y)=p_{0} x / a$ over the plate domain; for various values of the plate aspect ratio and comparison with the centre deflections evaluated and obtained previously by Onah et al [31] and Shames and Dym [2]

\begin{tabular}{|c|c|c|c|}
\hline \multirow{3}{*}{$b / a$} & \multicolumn{3}{|c|}{$w_{c}=\alpha_{1} \frac{p_{0} a^{4}}{D}$} \\
\cline { 2 - 4 } & $\begin{array}{c}\left(\alpha_{1}\right) \text { Present } \\
\text { study }\end{array}$ & $\begin{array}{c}\left(\alpha_{1}\right) \text { Onah et } \\
\text { al }[31]\end{array}$ & $\begin{array}{c}\left(\alpha_{1}\right) \text { Shames and } \\
\text { Dym [2] }\end{array}$ \\
\hline 0.5 & $8.1576 \times 10^{-5}$ & $8.1576 \times 10^{-5}$ & $8.1576 \times 10^{-5}$ \\
\hline 1.0 & $9.5855 \times 10^{-4}$ & $9.5855 \times 10^{-4}$ & $9.5855 \times 10^{-4}$ \\
\hline 2.0 & $4.2224 \times 10^{-3}$ & $4.2224 \times 10^{-3}$ & $4.2224 \times 10^{-3}$ \\
\hline
\end{tabular}

Table 2: Converged results for bending moments $M_{x x}$ at the centre of rectangular thin CSCS plate subjected to triangular load distribution $p(x, y)=p_{0} x / a$ over the domain of the plate ( $\mu=0.30$ ) for various values of the plate aspect ratio and comparison with previously obtained converged results by Onah et [31] and Timoshenko and Woinowsky-Krieger [1] for $M_{x x}$ evaluated at the plate centre

\begin{tabular}{|l|c|c|c|}
\hline \multirow{2}{*}{$\begin{array}{c}b / a \\
\text { aspect } \\
\text { ratio }\end{array}$} & \multicolumn{3}{|c|}{$M_{x x}$} \\
\cline { 2 - 4 } & $\begin{array}{c}\text { Present study } \\
M_{x x}\end{array}$ & $\begin{array}{c}\text { Onah et al } \\
{[31]} \\
M_{x x}\end{array}$ & $\begin{array}{c}\text { Timoshenko and } \\
\text { Woinowsky- } \\
\text { Krieger [1] } \\
M_{x x}\end{array}$ \\
\hline 0.5 & $0.007 p_{0} b^{2}$ & $0.007 p_{0} b^{2}$ & $0.007 p_{0} b^{2}$ \\
\hline 0.75 & $0.011 p_{0} b^{2}$ & $0.011 p_{0} b^{2}$ & $0.011 p_{0} b^{2}$ \\
\hline 1.0 & $0.0121760 p_{0} a^{2}$ & $0.012 p_{0} a^{2}$ & $0.012 p_{0} a^{2}$ \\
\hline 1.25 & $0.021 p_{0} a^{2}$ & $0.021 p_{0} a^{2}$ & $0.021 p_{0} a^{2}$ \\
\hline 1.50 & $0.030 p_{0} a^{2}$ & $0.030 p_{0} a^{2}$ & $0.030 p_{0} a^{2}$ \\
\hline 2 & $0.043 p_{0} a^{2}$ & $0.043 p_{0} a^{2}$ & $0.043 p_{0} a^{2}$ \\
\hline$\infty$ & $0.063 p_{0} a^{2}$ & $0.063 p_{0} a^{2}$ & $0.063 p_{0} a^{2}$ \\
\hline
\end{tabular}

Table 3: Converged results for bending moments $M_{y y}$ at the centre of rectangular thin CSCS plate subjected to triangular load distribution $p(x, y)=p_{0} x / a$ over the domain of the plate (for $\mu=0.30$ ) for various values of the plate aspect ratio; and comparative results for $M_{y y}$ at the plate centre for different values of plate aspect ratio as previously obtained by Onah et al [31] and Timoshenko and Woinowsky-Krieger [1]

\begin{tabular}{|l|c|c|c|}
\hline $\begin{array}{c}\text { aspect } \\
\text { ratio } \\
b / a\end{array}$ & \multicolumn{3}{|c|}{$M_{y y}$} \\
\cline { 2 - 4 } & Present study & Onah et al & Timoshenko and \\
& $M_{y y}$ & $\begin{array}{c}\text { Woinowsky- } \\
M_{y y}\end{array}$ & $\begin{array}{c}\text { Krieger [1] } \\
M_{y y}\end{array}$ \\
\hline 0.5 & $0.021 p_{0} b^{2}$ & $0.021 p_{0} b^{2}$ & $0.021 p_{0} b^{2}$ \\
\hline 0.75 & $0.020 p_{0} b^{2}$ & $0.020 p_{0} b^{2}$ & $0.020 p_{0} b^{2}$ \\
\hline 1.0 & $0.016617 p_{0} a^{2}$ & $0.017 p_{0} a^{2}$ & $0.017 p_{0} a^{2}$ \\
\hline 1.25 & $0.021 p_{0} a^{2}$ & $0.021 p_{0} a^{2}$ & $0.021 p_{0} a^{2}$ \\
\hline 1.50 & $0.023 p_{0} a^{2}$ & $0.023 p_{0} a^{2}$ & $0.023 p_{0} a^{2}$ \\
\hline 2 & $0.024 p_{0} a^{2}$ & $0.024 p_{0} a^{2}$ & $0.024 p_{0} a^{2}$ \\
\hline$\infty$ & $0.019 p_{0} a^{2}$ & $0.019 p_{0} a^{2}$ & $0.019 p_{0} a^{2}$ \\
\hline
\end{tabular}

Table 4: Convergence studies of the single series expression for the deflection at the centre of square CSCS Kirchhoff plate subjected to triangular load distribution $p(x, y)=p_{0} x / a$, over the entire plate domain. Comparative results for the convergence investigation of the expressions for deflection at the centre of CSCS thin plate obtained using KantorovichVlasov method by Onah et al [31] and Levy's method by Shames and Dym [2]. $u_{z}=\alpha_{1} p_{0} a^{4} / D$

\begin{tabular}{|c|c|c|}
\hline $\begin{array}{c}\text { Number of } \\
\text { terms in series }\end{array}$ & $\begin{array}{c}u_{z}=\left(\alpha_{1} p_{0} a^{4} / D\right) \\
\alpha_{1}\end{array}$ & $\begin{array}{c}\text { Onah et al [31], } \\
\text { Shames and } \\
\text { Dym [2] }\left(\alpha_{1}\right)\end{array}$ \\
\hline 1 & $9.8093 \times 10^{-4}$ & $9.8093 \times 10^{-4}$ \\
\hline 2 & $9.8093 \times 10^{-4}$ & $9.8093 \times 10^{-4}$ \\
\hline 3 & $9.5679 \times 10^{-4}$ & $9.5679 \times 10^{-4}$ \\
\hline 4 & $9.5679 \times 10^{-4}$ & $9.5679 \times 10^{-4}$ \\
\hline 5 & $9.5887 \times 10^{-4}$ & $9.5887 \times 10^{-4}$ \\
\hline 6 & $9.5887 \times 10^{-4}$ & $9.5887 \times 10^{-4}$ \\
\hline 7 & $9.5848 \times 10^{-4}$ & $9.5848 \times 10^{-4}$ \\
\hline 8 & $9.5848 \times 10^{-4}$ & $9.5848 \times 10^{-4}$ \\
\hline 9 & $9.5859 \times 10^{-4}$ & $9.5859 \times 10^{-4}$ \\
\hline 10 & $9.5859 \times 10^{-4}$ & $9.5859 \times 10^{-4}$ \\
\hline 11 & $9.5855 \times 10^{-4}$ & $9.5855 \times 10^{-4}$ \\
\hline 12 & $9.5855 \times 10^{-4}$ & $9.5855 \times 10^{-4}$ \\
\hline
\end{tabular}

Table 5: Convergence studies of the single series expressions for bending moments $M_{x x}$ and $M_{y y}$ at the centre of square CSCS Kirchhoff plate subjected to triangular load distribution $p(x, y)=p_{0} x / a$ over the entire domain of the plate. Comparative results for the investigation of the convergence of expressions of bending moments, $M_{x x}$ and $M_{y y}$ obtained by using Kantorovich-Vlasov variational method by Onah et al [31] and Levy's method by Shames and Dym [2]

\begin{tabular}{|c|c|c|c|c|}
\hline $\begin{array}{c}\text { Number } \\
\text { of terms } \\
\text { in series }\end{array}$ & $M_{x x}=\alpha_{2} p_{0} a^{2}$ & $\begin{array}{c}\text { Onah et } \\
\text { al [31]; } \\
\text { Shames } \\
\text { and } \\
\text { Dym [2] } \\
\alpha_{2}\end{array}$ & $M_{y y}=\alpha_{4} p_{0} a^{2}$ & $\begin{array}{c}\text { Onah et } \\
\text { al [31]; } \\
\text { Shames } \\
\text { and Dym } \\
{[2]} \\
\alpha_{2}\end{array}$ \\
\hline 1 & $1.4002 \times$ & $1.4002 \times$ & $1.7307 \times$ & $1.7307 \times$ \\
& $10^{-2}$ & $10^{-2}$ & $10^{-2}$ & $10^{-2}$ \\
\hline 2 & $1.4002 \times$ & $1.4002 \times$ & $1.7307 \times$ & $1.7307 \times$ \\
\hline
\end{tabular}


International Journal of Engineering Research and Technology. ISSN 0974-3154, Volume 13, Number 7 (2020), pp. 1802-1813

(C) International Research Publication House. https://dx.doi.org/10.37624/IJERT/13.7.2020.1802-1813

\begin{tabular}{|c|c|c|c|c|}
\hline & $10^{-2}$ & $10^{-2}$ & $10^{-2}$ & $10^{-2}$ \\
\hline 3 & $1.1810 \times$ & $1.1810 \times$ & $1.6505 \times$ & $1.6505 \times$ \\
& $10^{-2}$ & $10^{-2}$ & $10^{-2}$ & $10^{-2}$ \\
\hline 4 & $1.1810 \times$ & $1.1810 \times$ & $1.6505 \times$ & $1.6505 \times$ \\
& $10^{-2}$ & $10^{-2}$ & $10^{-2}$ & $10^{-2}$ \\
\hline 5 & $1.2324 \times$ & $1.2324 \times$ & $1.6661 \times$ & $1.6661 \times$ \\
& $10^{-2}$ & $10^{-2}$ & $10^{-2}$ & $10^{-2}$ \\
\hline 6 & $1.2324 \times$ & $1.2324 \times$ & $1.6661 \times$ & $1.6661 \times$ \\
& $10^{-2}$ & $10^{-2}$ & $10^{-2}$ & $10^{-2}$ \\
\hline 7 & $1.2136 \times$ & $1.2136 \times$ & $1.6605 \times$ & $1.6605 \times$ \\
& $10^{-2}$ & $10^{-2}$ & $10^{-2}$ & $10^{-2}$ \\
\hline 8 & $1.2136 \times$ & $1.2136 \times$ & $1.6605 \times$ & $1.6605 \times$ \\
& $10^{-2}$ & $10^{-2}$ & $10^{-2}$ & $10^{-2}$ \\
\hline 9 & $1.2224 \times$ & $1.2224 \times$ & $1.6632 \times$ & $1.6632 \times$ \\
& $10^{-2}$ & $10^{-2}$ & $10^{-2}$ & $10^{-2}$ \\
\hline 10 & $1.2224 \times$ & $1.2224 \times$ & $1.6632 \times$ & $1.6632 \times$ \\
& $10^{-2}$ & $10^{-2}$ & $10^{-2}$ & $10^{-2}$ \\
\hline 11 & $1.2176 \times$ & $1.2176 \times$ & $1.6617 \times$ & $1.6617 \times$ \\
& $10^{-2}$ & $10^{-2}$ & $10^{-2}$ & $10^{-2}$ \\
\hline 12 & $1.2176 \times$ & $1.2176 \times$ & $1.6617 \times$ & $1.6617 \times$ \\
& $10^{-2}$ & $10^{-2}$ & $10^{-2}$ & $10^{-2}$ \\
\hline
\end{tabular}

the plate and the deflection expression at the plate centre was found as Equation (68). Equation (68) is presented in terms of deflection coefficients $\alpha_{1}$ as Equation (69) where $\alpha_{1}$ is expressed as the single infinite series expressed by Equation (70).

The bending moment expressions were found by using the single infinite series expression for $u_{z}(x, y)$ in the bending moment-deflection equations. The expression for $M_{x x}$ was found as the single infinite series given generally by Equation (76), which can be expressed using bending moment coefficients for $M_{x x}\left(\alpha_{2}\right.$ and $\left.\alpha_{3}\right)$ as Equation (77). Similarly, the expression for $M_{y y}$ was found as the single infinite series given generally by Equation (78), which can be expressed using bending moment coefficients for $M_{y y}\left(\alpha_{4}\right.$ and $\left.\alpha_{5}\right)$ as Equation (79).

The expressions obtained were used to compute the solution for square CSCS plate under triangular loading distribution. A one term approximation was found for the centre deflection as Equation (86), and the bending moments at the centre as Equation (89) for $M_{x x}$ and Equation (90) for $M_{y y}$.

The single infinite series for the deflection was used to obtain the converged solutions for deflection of the centre of CSCS plate for various values of the aspect ratio $(b / a)$ and the results presented in Table 1, which shows that the results are in excellent agreement with previously presented results by Shames and Dym [2] and Onah et [31]. The expression for $M_{x x}$ was used to determine the bending moments $M_{x x}$ at the centre of the plate for $\mu=0.30$ and various values of the aspect ratio $(b / a)$ and the results were presented in Table 2 . Table 2 illustrates the excellent agreement of the present results for $M_{x x}$ with the previous results obtained by Timoshenko and Woinowsky-Krieger [1] and Onah et al [31].

The expression for $M_{y y}$ was used to determine the bending moment $M_{y y}$ at the centre of the plate for $\mu=0.30$, and various values of the plate aspect ratio $(b / a)$ and the results were presented in Table 3. Table 3 illustrates the excellent agreement of the present results for $M_{y y}$ with the previous results obtained by Timoshenko and Woinowsky-Krieger [1] and Onah et al [31].

The results of the investigation of the convergence properties of the infinite series for the deflection, which are presented in Table 4 for square CSCS plate show the series for the deflection is a rapidly convergent series. Table 4 also demonstrates that the results of the convergence studies of the expression for deflection are identical with previous results presented by Shames and Dym [2] and Onah et al [31], who used Levy's method and Kantorovich-Vlasov's method respectively. The investigation of the convergence properties of the expressions for bending moments $M_{x x}$ and $M_{y y}$ which are presented in Table 5 for square CSCS plates show that both series are rapidly convergent. Table 5 shows that the results of the convergence studies for the bending moment expressions at the centre of square CSCS plate are identical with previous results of convergence investigations presented by Shames and Dym [2\} and Onah et [31]. 
International Journal of Engineering Research and Technology. ISSN 0974-3154, Volume 13, Number 7 (2020), pp. 1802-1813

(C) International Research Publication House. https://dx.doi.org/10.37624/IJERT/13.7.2020.1802-1813

\section{CONCLUSION}

(1) The single finite Fourier sine integral transform method is a very effective mathematical tool for solving the flexural analysis problem of rectangular Kirchhoff CSCS plates subject to triangular load distribution over the plate region.

(2) The governing domain equation which is an inhomogeneous biharmonic partial differential equation is converted by the transformation to an integral equation over the solution domain.

(3) The integral equation is reduced by the linearity properties of the transformation, the Leibnitz rule and the boundary conditions along the simply supported edges to ordinary differential equations (ODEs).

(4) The general solution to the ODEs obtained using the method of trial functions but which could also be obtained using other methods of solving ODEs such as Differential Operator (D-operator) methods, variational of parameters methods, etc gave the expression for $u_{z}(x, y)$ that satisfies the domain PDE at all points in the solution domain in terms of the integration constants $c_{1 n}$ and $c_{2 n}$.

(5) The enforcement of boundary conditions along the clamped edges $y= \pm b / 2$ was used to obtain the expressions for the integration constants $c_{1 n}$ and $c_{2 n}$, thus leading to the full determination of the solution for the deflection $u_{z}(x, y)$ for all points in the solution domain and on the clamped boundaries $(y= \pm b / 2)$.

(6) The obtained solution for transverse deflection $u_{z}(x, y)$ is a single infinite series with rapidly convergent properties.

(7) The expression for transverse deflection $u_{z}(x, y)$ is used to determine the expressions for the bending moments $M_{x x}$ and $M_{y y}$ at any point in the plate. The expressions for $M_{x x}$ and $M_{y y}$ are single infinite series that are also rapidly convergent as demonstrated in the calculations done and presented for square CSCS plate considered.

(8) Maximum deflection was obtained at the plate centre and this result agrees with the symmetrical features of the presented problem.

(9) The converged values of deflection and bending moments calculated at the plate centre are in excellent agreement with previous results published by Timoshenko and Woinowsky-Krieger [1], Onah et al [31] and Shames and Dym [2] and that employed superposition method, Kantorovich-Vlasov's and Levy's methods respectively..

(10) The single finite integral transform method has yielded exact solutions for the flexural problem of rectangular CSCS plates under triangular loading distribution since the governing domain equation is satisfied at every point in the solution domain, and at every point on the boundaries of the CSCS plate considered.

\section{Nomenclature/Notations}

$\begin{array}{ll}\text { ODE(s) } & \text { Ordinary Differential Equations(s) } \\ \text { 3D } & \text { three-dimensional } \\ \text { 2D } & \text { two-dimensional }\end{array}$

CSCS plate: plate with two opposite sides simply supported and the other two sides clamped.

$x, y, z \quad$ Cartesian coordinates

$\begin{array}{ll}\mu & \text { Poisson's ratio } \\ h & \text { plate thickness } \\ p(x, y) & \text { transverse load distribution over the plate domain } \\ D & \text { flexural rigidity of plate material } \\ u_{z}(x, y) & \text { transverse deflection of the plate middle surface. } \\ M_{x x} M_{y y} & \text { Bending moment distributions } \\ E & \text { Young's modulus of elasticity of the plate } \\ & \text { material } \\ a & \text { inplane dimension of the plate in the } x \text { direction } \\ b & \text { inplane dimension of the plate in the } y \text { direction. } \\ p_{0} & \text { intensity of triangular load distribution at } x=a . \\ S_{n} & \text { single finite Fourier sine integral transform } \\ \text { operator } & \\ 0 \leq x \leq l & \text { interval of definition of } x \text { for } v(x) \\ v(x) & \text { a function defined in terms of } x \\ v(x, y) & \text { a function defined in terms of } x \text { and } y \\ V_{s}(n) & \text { single finite Fourier sine transform of } v(x) \\ C_{n}(v(x)) \text { or } & V_{c}(n) \text { single finite Fourier cosine integral transform } \\ & \text { of } v(x) \\ n & \text { single finite Fourier sine integral transform } \\ & \text { parameter. }\end{array}$

$\frac{d^{k}}{d x^{k}} k$ th $\quad$ derivative with respect to $x$

$\int \quad$ integral

$\int_{0}^{a}() d x$ integration with respect to $x$ between the intervals $x=0$ and $x=a$.

$\bar{U}_{z}(n, y)$ single finite Fourier integral transform of the deflection $u_{z}(x, y)$ of the plate.

$\Gamma, \lambda$ parameters of the assumed homogeneous solution for the ordinary differential equation in the transform space resulting from the application of the transformation to the governing domain equation.

$\bar{U}_{z h}(n, y)$ homogeneous component of the general solution for $\bar{U}_{z}(n, y)$

$\lambda_{1,2}, \lambda_{3,4}$ four roots of the resulting algebraic eigenequation involving $\lambda$

$c_{1 n}, c_{2 n}, c_{3 n}, c_{4 n}$ integration constants

$\bar{U}_{z p}(n, y)$ particular integral (solution) for the general solution of the ordinary differential equation in transform space

$\sum \quad$ summation

$\infty \quad$ infinity

$F_{1} \quad$ parameter defined in terms of $n, a$ and $b$

$F_{2} \quad$ another parameter defined in terms of $n, a$ and $b$

$\alpha_{1} \quad$ deflection coefficient for the centre of rectangular CSCS Kirchhoff plate subjected to triangular load distribution over the entire plate domain

$\alpha_{2} \quad$ bending moment coefficient for $M_{x x}$ at the plate centre when $M_{x x}$ is expressed using a

$\alpha_{3} \quad$ bending moment coefficient for $M_{x x}$ at the plate centre when $M_{x x}$ is expressed using $b$ 
$\alpha_{4}$

$\alpha_{5}$

$\frac{\partial^{k}}{\partial x^{k}}$

$\cos$

$\sin$

cosh

$\sinh$

coth bending moment coefficient for $M_{y y}$ at the plate centre where $M_{y y}$ is expressed using $a$

bending moment coefficient for $M_{y y}$ at the plate centre where $M_{y y}$ is expressed using $b$

$k$ th partial derivative with respect to $x$

cosine function

sine function

hyperbolic cosine function

hyperbolic sine function

hyperbolic cotangent function.

\section{Conflict of interest}

The authors declare no conflict of interest in the publication of this paper.

\section{REFERENCES}

[1] Timoshenko S., Woinowsky-Krieger S., 1959. Theory of Plates and Shells. McGraw Hill Book Company, Tokyo.

[2] Shames I.H., Dym C.L., 2006. Energy and Finite Element Methods in Structural Mechanics, New Age International Publishers, New Delhi.

[3] Ventsel E., Krauthammer T., 2001. Thin Plates and Shells: Theory, Analysis and Applications. Marcel Dekker Inc. New York, USA.

[4] Chandrashekhera K., 2001. Theory of Plates. Universities Press (India) Limited Hyderabad.

[5] Balasubramanian A., 2011. Plate Analysis with Different Geometries and Arbitrary Boundary Conditions, MSc Thesis, Mechanical Engineering, Faculty of Graduate School, The University of Texas at Arlington Dec 2011.

[6] Ike C.C., 2018. First principles derivation of differential equations of equilibrium of anisotropic thin plates on elastic foundations, Journal of Geotechnical and Transportation Engineering, Vol 4, Issue 1, pp 10 - 16.

[7] Szilard R., 2004. Theories and Applications of Plate Analysis: Classical, Numerical and Engineering Methods, John Wiley and Sons Inc. New York pp 1056.

[8] Mansfield E.H., 2005. The Bending and Stretching of Plates Second Edition, Cambridge Universities Press, Cambridge.

[9] Lin Y., 1987. A mathematical theory of elastic orthotropic plates in plane strain and axi-symmetric deformations, PhD Thesis, Faculty of Graduate Studies, Department of Mathematics, Institute of Applied Mathematics The University of British Columbia, June 1987.

[10] Heintz D., 2011. Adaptive finite element methods for plate bending problems, $\mathrm{PhD}$ Thesis, Department of Mathematical Sciences, Chalmers University of Technology and University of Gothenburg, Göteborg, Sweden.

[11] Ike C.C., 2017. Equilibrium approach in the derivation of differential equations for homogeneous Mindlin plates, Nigerian Journal of Technology, Vol 36, No 2, April, pp 346 - 350.

[12] Ike C.C., 2017.Variational formulation of the Mindlin plate on Winkler foundation problem, Electronic Journal of Geotechnical Engineering, Vol 22.12, pp $4829-4846$.

[13] Ike C.C.,Nwoji C.U., Ofondu I.O., 2017. Variational formulation of Mindlin plate equation and solution for deflections of clamped Mindlin plates, International Journal for Research in Applied Sciences and Engineering Technology, Vol 5, Issue 1, Jan. pp 340 353.

[14] Nwoji C.U., Onah H.N., Mama B.O., Ike C.C., 2017. Theory of elasticity formulation of the Mindlin plate equations, International Journal of Engineering and Technology, Vol 9, No 6, Dec 2017 - Jan 2018, pp $4344-4352$.

[15] Ike C.C., 2018, Mathematical solutions for the flexural analysis of Mindlin's first order shear deformable circular plates, Journal of Mathematical Models, Vol 4 ,Issue 2, pp $50-72$.

[16] Nwoji C.U., Mama B.O., Onah H.N., Ike C.C., 2018. Flexural analysis of simply supported rectangular Mindlin plates under bisinusoidal transverse load, ARPN Journal of Engineering and Applied Sciences, Vol 13, No 15, pp 4480 - 4488.

[17] Onah H.N., Onyia M.E., Mama B.O., Nwoji C.U., Ike C.C., 2020. First principles derivation of displacement and stress functions for three-dimensional elastostatic problems and application to the flexural analysis of thick circular plates, Journal of Computational Applied Mechanics, Vol. 51, Issue 1, June 2020 pp 184 - 198. DoI: 10.22059/JCAMECH.2020.295989.471.

[18] Ezeh J.C., Ibearugbulem O.M., Onyechere C.I., 2013. Pure bending analysis of thin rectangular flat plates using ordinary finite difference method, International Journal of Emerging Technology and Advanced Engineering, Vol 3, Issue 3, March 2013, pp 20 - 23.

[19] Osadebe N.N., Ike C.C., Onah H., Nwoji C.U., F.O. Okafor F.O., 2016. Application of the Galerkin-Vlasov method to the flexural analysis of simply supported rectangular Kirchhoff plates under uniform loads, Nigerian Journal of Technology, Vol 35, No 4, October pp $732-738$.

[20] Nwoji C.U., Mama B.O., Ike C.C., Onah H.N., 2017. Galerkin-Vlasov method for the flexural analysis of rectangular Kirchhoff plates with clamped and simply supported edges, IOSR Journal of Mechanical and Civil Engineering, Vol 14, Issue 2, Version 1, March April, pp $61-74$.

[21] Ike C.C., 2018, Flexural analysis of rectangular Kirchhoff plate on Winkler foundation using GalerkinVlasov variational method, Mathematical Modelling of Engineering Problems, Vol 5, No 2, June pp 83 - 92.

[22] Mama B.O., Ike C.C., 2018. Galerkin-Vlasov method for deflection analysis of isotropic sandwich plates under uniform load. Journal of Engineering, Vol 5, Issue 1, pp D15 - D19.

[23] Onyia M.E., Rowland-Lato E.O., Ike C.C., 2020. Galerkin-Vlasov variational method for the elastic 
buckling analysis of SSCF and SSSS rectangular plates, International Journal of Engineering Research and Technology, Vol 13, No 6, pp 1137 - 1146.

[24] Mama B.O., Onah H.N., Ike C.C., Osadebe N.N., 2017. Solution of free harmonic vibration equation of simply supported Kirchhoff plate by Galerkin-Vlasov method, Nigerian Journal of Technology, Vol 36, No 2, April pp $361-365$.

[25] Ike C.C., 2018. Systematic presentation of Ritz variational method for the flexural analysis of simply supported rectangular Kirchhoff-Love plates. Journal of Engineering Sciences, Vol 5, Issue 2, pp D1 - D5.

[26] Ike C.C., 2018. Ritz variational method for the flexural analysis of rectangular Kirchhoff plate on Winkler foundation. Journal of Engineering Sciences, Vol 6, Issue 1, pp D7 - D15.

[27] Nwoji C.U., Onah H.N., Mama B.O., Ike C.C., 2018. Ritz variational method for bending of rectangular Kirchhoff-Love plate under transverse hydrostatic load distribution, Mathematical Modelling of Engineering Problems, Vol 5, No 1, March, pp $1-10$.

[28] Ike C.C., 2017. Kantorovich-Euler Lagrange-Galerkin method for bending analysis of thin plates, Nigerian Journal of Technology, Vol 36, No 2, April, pp 351 360.

[29] Ike C.C., Nwoji C.U., 2017. Kantorovich method for the determination of eigenfrequencies of thin rectangular plates, Explorematics Journal of Innovative Engineering and Technology, Vol 01, No 01, September, pp $20-27$.

[30] Nwoji C.U., Mama B.O., Onah H.N., Ike C.C., 2017. Kantorovich-Vlasov method for simply supported plates under uniformly distributed loads. International Journal of Civil, Mechanical and Energy Science Vol 3 Issue 2, March - April pp 69 - 77.

[31] Onah H.N., Mama B.O., Ike C.C., Nwoji C.C., 2017. Kantorovich-Vlasov method for the flexural analysis of Kirchhoff plates with opposite edges clamped and simply supported (CSCS plates), International Journal of Engineering and Technology, Vol 9, No 6, Dec 2017 - Jan. 2018, pp 4333 - 4343.

[32] Ike C.C., Mama B.O., 2018. Kantorovich variational method for the flexural analysis of CSCS KirchhoffLove plates, Journal of Mathematical Models, Vol 4, Issue 1 , pp $29-41$.

[33] Ike C.C., Nwoji C.U., Ikwueze E.U., Ofondu I.O., 2017. Bending analysis of simply supported rectangular Kirchhoff plates under linearly distributed transverse load, Explorematics Journal of Innovative Engineering and Technology, Vol 01, No 01, September, pp 28 - 36.

[34] Ike C.C., 2017. Flexural analysis of Kirchhoff plates on Winkler foundations using finite Fourier sine transform method, Mathematical Modelling of Engineering Problems, Vol 4, No 4, pp $145-154$.

[35] Nwoji C.U., Onah H.N., Mama B.O., Ike C.C., Ikwueze E.U., 2017. Elastic buckling analysis of simply supported thin plates using the double finite Fourier sine transform method, Explorematics Journal of Innovative Engineering and Technology, Vol 01, No 01, September, pp $37-47$.
[36] Mama B.O., Ike C.C., Onah H.N., Nwoji C.U., 2017. Analysis of rectangular Kirchhoff plate on Winkler foundation using finite Fourier sine transform method, IOSR Journal of Mathematics, Vol 13, Issue 1, Version VI, Jan - Feb pp $58-66$.

[37] Mama B.O., Nwoji C.U., Ike C.C., Onah H.N., 2017. Analysis of rectangular Kirchhoff plates by the finite Fourier sine transform method, International Journal of Advanced Engineering Research and Science, Vol 4, Issue 3, March, pp 285 - 291.

[38] Mama B.O., Ike C.C., Nwoji C.U.,Onah H.N., 2018. Double finite sine transform method for deflection analysis of isotropic sandwich plates under uniform load, Advances in Modelling and Analysis A, Vol 55, No 2, June pp $76-81$.

[39] Onah H.N., Nwoji C.U., Ike C.C., Mama B.O., 2018. Elastic buckling analysis of uniaxially compressed CCSS Kirchhoff plate using single finite Fourier sine integral transform method, Modelling Measurement and Control B, Vol 87, No 2, June 2018, pp 107 - 111.

[40] Ike C.C., 2018. Double Fourier cosine series method for the flexural analysis of Kirchhoff plates on Winkler foundations, Journal of Geotechnical and Transportation Engineering, Vol 4, Issue 2, pp 30 - 38.

[41] Oguaghamba O.A., Ike C.C., 2020. Single finite Fourier sine integral transform method for the determination of natural frequencies of flexural vibration of Kirchhoff plates, International Journal of Engineering Research and Technology, Vol 13, No 3, pp 470 - 476.

[42] Onyia M.E., Rowland-Lato E.O., Ike C.C., 2020. Elastic buckling analysis of SSCF and SSSS rectangular thin plates using the single finite Fourier sine integral transform method, International Journal of Engineering Research and Technology, Vol 13, No 6, pp 1147 1158 .

[43] Ghannadiasi A., Noorzad A., 2016. Bending solution for simply supported annular plates using the indirect Trefftz boundary method, Civil Engineering Infrastructures Journal, Vol 49, Issue 1, pp 127 - 138 June 2016.

[44] Bidgoli A.M.M., Daneshmehr A.R., Kolahchi R., 2015. Analytical bending solution of fully clamped orthotropic rectangular plates resting on elastic foundations by the finite integral transform method, Journal of Applied and Computational Mechanics, Vol 1 , Issue 2, pp $52-58$.

[45] Zargaripoor A., Bahrami A., Nikkah-Bahrami M., 2018. Free vibration and buckling analysis of third order shear deformation theory using exact wave propagation approach, Journal of Computational Applied Mechanics, Vol 49, Issue 1, pp $86-101$.

[46] Goodarzi M., Nikkah-Bahrami M., Tavaf V., 2017. Refined plate theory for free vibration analysis of FG nanoplates using the nonlocal continuum plate model, Journal of Computational Applied Mechanics, Vol 48, Issue 1 , pp 123 - 146.

[47] Javidi R., Zand M.M., Dastani K., 2018. Dynamics of nonlinear rectangular plates subjected to an orbiting mass based on shear deformation plate theory, Journal 
of Computational Applied Mechanics, Vol 49, Issue 1, pp $27-36$.

[48] Makvandi H., Moradis S., Poorveis D., Shirazi K.H., 2017. A new approach for nonlinear vibration analysis of thin and moderately thick rectangular plates under inplane compressive load, Journal of Computational Applied Mechanics, Vol 48, Issue 2, pp 185 - 198.

[49] Sayyad A., Ghugal Y.M., 2018. Bending of shear deformable plates resting on Winkler foundations according to trigonometric plate theory, Journal of Applied and Computational Mechanics, Vol 4, Issue 3, pp $187-201$.

[50] Mirzapour A., Eskandari-Ghadi M., ArdeshirBelhrestaghi A., 2012. Analysis of transversely isotropic half spaces under the effect of bending of a rigid circular plate, Civil Engineering Infrastructures Journal, Vol 45, Issue 5, pp $601-610$.

[51] Shahabian F., Elachachi S.M., Breysse D, 2003. Safety analysis of the patch load resistance of plate girders: Influence of model error and variability, Civil Engineering Infrastructures Journal, Vol 46, Issue 2, pp $145-160$.

[52] Abdollahzadeh G., Ghobadi F., 2014. Mathematical modelling of column-base connections under monotonic loading, Civil Engineering Infrastructures Journal, Vol 47, Issue 2, pp 255 - 272.

[53] Cuba L., Arciniega R.A., Mantavi J.L., 2019. Generalized 2 unknowns HSDT to study isotropic and orthotropic composite plates, Journal of Applied and Computational Mechanics, Vol 5, Issue 1, pp 141 149.

[54] Jahanpour A., Roozbahani F., 2016. An applicable formula for elastic buckling of rectangular plates under biaxial and shear loads. Aerospace Science and Technology, Vol 56, pp $100-111$.

[55] Tufa Negero N., 1958, Integral transforms for applications to partial differential equations, Grumman Aircraft Engineering Corporation Research Department Report, RE-103 September 1958.

[56] Al-Khaled K., 2018, Finite Fourier transform for solving potential and steady-state temperature problems, Advances in Difference Equations, Vol 98, pp $1-14$

[57] Jim Lambers, The Finite Transform, MAT 417/517, Spring Semester 2013 - 14, Lecture 18 Notes, retrieved from https://www.math.usm.edu on $28^{\text {th }}$ Jan 2020.

[58] Sine and Cosine Transforms for finite range, retrieved from mx.nthu.edu.tw, on $20^{\text {th }}$ Jan 2020.

[59] Britanak V., Yip P.C., Rao K.R., 2006. Discrete Cosine and Sine Transforms: General Properties Fast Algorithms and Integer Approximations, Elsevier Ltd pp 368.

[60] Brown D., 2002. Integral Transforms and their Applications, Third Edition, Texts in Applied Mathematics, 41, Springer.

[61] Lokenath D. and Bhatta D., 2007. Integral transforms and their applications, Second Edition, Chapman and Hall/CRC Taylor and Francis Group LLC, New York.

[62] Antimorov M.Ya, Kalyshkin A., Vaillanconot Remi, 1993. Applied Integral Transforms, Center des
Researches Mathematiques, Universite de Montreal Volume 2, CRM Monograph Series American Mathematical Society Providence, Rhode Island, USA.

[63] Andrews L.C., Shivamoggi B.K., 1999. Integral Transforms for Engineers, University of Central Florida, SPIE Optical Engineering of Press. A Publication of SPIE, The International Society for Optical Engineering, Bellingham Washington, USA. 